\title{
Is the health system in the Islamic Republic of Iran ready to deal with the effects of drought?
}

Reza Dehnavieh, ${ }^{1}$ Keyhan Sajadi ${ }^{1}$ and Simin Salehinejad ${ }^{2}$

${ }^{1}$ Health Foresight and Innovation Research Center, Institute for Futures Studies in Health, Kerman University of Medical Sciences, Kerman, Islamic Republic of Iran. ${ }^{2}$ Medical Informatics Research Center, Institute for Future Studies in Health, Kerman University of Medical Sciences, Kerman, Islamic Republic of Iran. (Correspondence to: Simin Nejad: s_salehi@kmu.ac.ir).

Citation: Dehnavieh R; Sajadi K; Salehinejad S. Is the health system in the Islamic Republic of Iran ready to deal with the effects of drought? East Mediter Health J. 2020;26(8):881-883. https://doi.org/10.26719/emhj.20.093

Received: 12/05/19; accepted: 21/10/19

Copyright (C) World Health Organization (WHO) 2020. Open Access. Some rights reserved. This work is available under the CC BY-NC-SA 3.o IGO

license (https://creativecommons.org/licenses/by-nc-sa/3.o/igo)

According to the Food and Agriculture Organization of the United Nations, since the year 1900 more than 11 million people have died as a result of drought and more than 2 billion have been affected by drought (1).

The Islamic Republic of Iran is located in arid and semi-arid regions and has experienced several major droughts. For example, over the past 40 years, the country has had more than 27 droughts (2). Figure 1 shows areas of the country affected by drought in 2016-2017.

Studies show that drought conditions will intensify in the coming years: in 2025, 2032, 2034, 2035 and 2039, most parts of the country are likely to face severe or moderate droughts (4). In particular, the drought situation will be much more critical in 2039; it is estimated that most parts of the country will have less than normal rainfall in this year and will face extreme and severe drought. Only small parts of the west, north-west, south-west and south of the country will not be badly affected (4).

Droughts can have a substantial impact on society, the environment and the economy, as well as human health. The main health effects of drought are related to nutrition, waterborne disease, airborne and dust-related disease, vector-borne disease, mental health and other

\section{Figure 1 Area affected by drought in the Islamic Republic of} Iran, 2016-2017 (3)

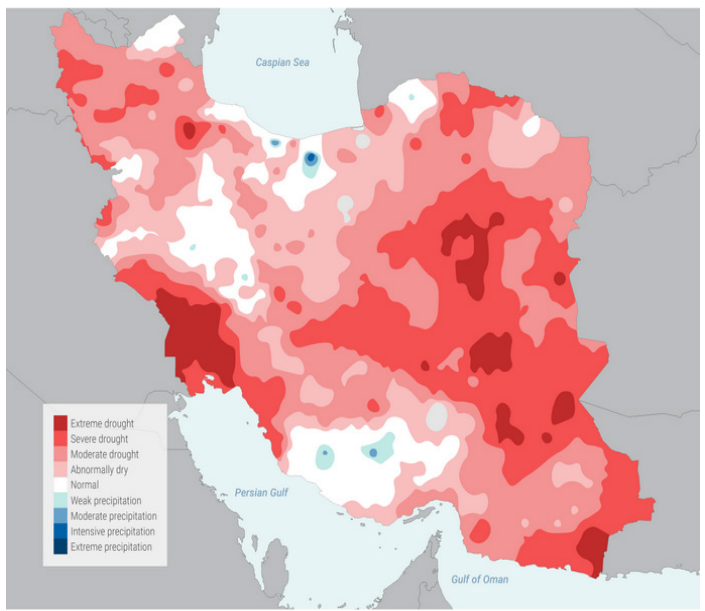

health conditions, and as a consequence of wildfires, migration and damage to infrastructure (5).

Malnutrition is one of the most obvious consequences of drought. According to the International Human Dimensions Programme on Global Environmental Change in 2015, the estimated annual risk of wheat and rice yield loss as a result of drought is high in the Islamic Republic of Iran (6). This situation can have a negative effect on nutrition and health because rice and wheat are the most popular food and agricultural products in this country (6). In addition, diseases transmitted by contaminated water and food (different types of diarrhoea, gastroenteritis and hepatitis) and by lack of water for personal hygiene (scabies, impetigo and conjunctivitis) are another impact of drought. About 5500 outbreaks of water- and foodborne diseases were recorded in the Islamic Republic of Iran between 2015 and 2016 (7). Drought may not be the only cause of water- and foodborne diseases, but it can intensify them, especially in areas where such diseases are endemic. Furthermore, some vector-borne diseases increase in drought periods, such as malaria, which is endemic in southern and southeastern parts of the country, and fascioliasis, which is endemic in western parts (8).

As soil becomes increasingly dry during a drought, dust in particular increases in the air. This dust can cause airborne/dust-related disease such as respiratory infection (sinusitis, pneumonia and mycoses), and respiratory and cardiovascular diseases, especially in high-risk groups such as older adults and people who have severe underlying medical conditions (e.g. heart or lung diseases or diabetes). A survey in the Islamic Republic of Iran showed that with a $1 \%$ increase in air pollution caused by dust, hospitalized respiratory patients will increase by about $0.5 \%$ and hospitalized cardiac patients by about $1 \%$, and cardiac deaths will increase by about $0.3 \%$ (9).

Migration and mental health are also affected drought because of the financial effects and the increased economic pressure on people, especially in agriculturebased regions in the Islamic Republic of Iran, where water scarcity affects most of the population. In many provinces, people are facing serious shortages of safe drinking-water and are therefore forced to migrate to 
other villages or cities (10). Regardless of the stimulus for migration, recent research provides evidence that mental health and well-being among migrant populations are worse than among native populations (11,12).

All the issues mentioned above can have an impact on theinfrastructureanddeliveryofhealthservices. Droughts can put pressure on health care providers because of an increase in the number of referrals and the workload of the medical staff as a result of the shortage of personnel due to their migration and unequal distribution. On the other hand, lack of a water supply in health services can increase the likelihood of contamination of instruments and hence reduce the ability of health professionals to perform their tasks. Therefore, droughts can increase the risk of disruption to health care and a deterioration in the health of affected people. Disruption of the power supply due to water shortage can also be a problem for the use of medical equipment and cooling systems for drugs and vaccines $(13,14)$. In the Islamic Republic of Iran with its wide population distribution and the poor infrastructure of the health system, these effects can be intensified.

One of the problems that health centres face if there is no pre-disaster planning is the lack of equipment, materials and human resources, and a system for identifying resources and allocating them to prioritized needs (15). For example, the health sector does not play an active role in tackling dust problems, which are one of the consequences of drought in the Islamic Republic of Iran (16).

One of the first field studies on reproductive health management in regions of the Islamic Republic of Iran affected by drought found that several factors affected reproductive health management. These factors were: disregard of cultural issues, lack of training of health care workers and drought-affected people, lack of planning, insufficient data collection, neglect of male reproductive health, and lack of a monitoring system on the planning for and response to the drought (17). On the other hand, health care providers such as nurses and vulnerable people, despite their important role in disaster management and planning, had little awareness about participation in the response phase of the disaster, were less prepared and performed poorly in this phase (18).

These findings should alert the policy-makers that steps need be taken to improve disaster preparedness and response, particularly since drought is a serious climate problem that will worsen in the coming years in the Islamic Republic of Iran.
Given the important role of the health sector in all phases of drought risk management and considering the problems discussed above, we recommend the following key actions.

- Provide proper planning and surveillance.

- Analyse local and regional health conditions based on a drought scenario.

- Study epidemiological characteristics of the population, available resources and health needs.

- Provide a local contingency plan to respond to the public health emergencies caused by drought.

- Develop a surveillance system to monitoring functions linked with primary health care.

- Plan for the development of resources and services for disease epidemics and outbreaks, and for surveillance of no communicable diseases in affected communities.

- Continuously assess current actions in order to plan for future actions.

- Increase knowledge about the role of the social environment on health during climate migration.

- Strengthen the data collection system in drought-affected areas.

- Strengthen communication and collaboration with relevant health organizations.

- Enhance the relationship between the main bodies involved in the drought response (organizational, local and regional).

- Connect health professionals and disaster managers.

- Empower human resources.

- Develop and train health teams for monitoring and assisting; provide health education for health care workers and vulnerable people.

- Strengthen food-safety measures.

- Develop monitoring programmes for water and food, and ensure their safety during transportation.

- Promote food and nutrition interventions that support measures for poverty alleviation, and ensure food accessibility and availability.

\section{References}

1. Drought. Rome: Food and Agriculture Organization of the United Nations; 2013 (www.fao.org/3/aq191e/aq191e.pdf, accessed 11 May 2019).

2. [Review of recent droughts in the country with an emphasis on consequences and efficient management requirements.] Tehran: Islamic Parliament Research Center (IPRC); 2011 (in Farsi). 
3. Asanjan AA, Faridzad M, Hayatbini N, Gorooh VA, Sadeghi M, Shearer EJ, et al. An assessment of the unprecedented extreme precipitation events over Iran: from satellite perspective. Irvine (CA): University of California; 2019 (http://chrs.web.uci.edu/articles/iran_rainfall.pdf, accessed 11 May 2019).

4. Khazanehdari I, Zabol Abbasi S, Kouhi M, Malbousi S. [Perspectives on the drought situation in Iran over the next thirty years.] J Geogr Reg Dev. 2009;12:1-17 (in Farsi).

5. Stanke C, Kerac M, Prudhomme C, Medlock J, Murray V. Health effects of drought: a systematic review of the evidence. PLoS currents. 2013;5. https://doi.org/10.1371/currents.dis.7a2ceege980f91ad7697b570bcc4boo4

6. Shi P, Kasperson R, editors. World atlas of natural disaster risk. Berlin: Springer-Verlag; 2015:229-45.

7. Nezhad SY, Jazani RK, Jahangiri K. Effective factors on outbreaks of food and water borne diseases in Iran: a trend analysis. Indian J Forensic Med Toxicol. 2019;13(2):268-72. https://doi.org/10.5958/0973-9130.2019.00129.4

8. Alpino TA, de Sena AR, de Freitas CM. Disasters related to droughts and public health - a review of the scientific literature. Cien saude colet. 2016;21(3):809-20. https://doi.org/10.1590/1413-81232015213.21392015

9. Delangizan S, Jafari Motlagh Z. [Dust phenomenon effects on cardiovascular and respiratory hospitalizations and mortality: a case study in Kermanshah during March-September 2010-2011.] Iran J Health Environ. 2013;6(1):65-76 (in Farsi).

10. United Nations technical mission on the drought situation in the Islamic Republic of Iran. New York: United Nations; 2000 (https://reliefweb.int/sites/reliefweb.int/files/resources/F_R_138.pdf, accessed 9 August 2011).

11. Goldman N, Pebley AR, Creighton MJ, Teruel GM, Rubalcava LN, Chung C. The consequences of migration to the United States for short-term changes in the health of Mexican immigrants. Demography. 2014;51(4):1159-73. https://doi.org/10. https://doi. org/10.1007/s13524-014-0304-y

12. Cantor-Graae E, Pedersen CB. Full spectrum of psychiatric disorders related to foreign migration: a Danish population-based cohort study. JAMA psychiatry. 2013;70(4):427-35. https://doi.org/10.1001/jamapsychiatry.2013.441

13. Grigoletto JC, Cabral AR, Bonfim CV, Rohlfs DB, Silva ELE, de Queiroz FB, et al. Management of health sector actions in drought situations. Cien saude colet. 2016;21(3):709-18. https://doi.org/10.1590/1413-81232015213.26212015

14. Ardalan A, Khankeh H, Mehrabi A, Nejatti A, Masoumi GR, Hajebi A. [Text book of health in emergencies \& disasters, first edition]. Tehran: Mehrravash; 2016 (in Farsi).

15. Allahbakhshi K, GhomianZ, Jazani R, Khorasani-Zavareh D. Preparedness challenges of the Iranian health system for dust and sand storms: A qualitative study. J Educ Health Promot. 2019;8(1):114. https://doi.org/10.4103/jehp.jehp_470_18

16. Mehrdad R. Health system in Iran. Japan Med Assoc J. 2009;52(1):69-73.

17. Sohrabizadeh S, Jahangiri K, Khani Jazani R. Reproductive health in the recent disasters of Iran: a management perspective. BMC Public Health. 2018;18(1):389. https://doi.org/10.1186/s12889-018-5311-2

18. Nakhaei M, Khankeh H R, Masoumi G, Hosseini M A, Parsa-Yekta Z. Health management in disasters in Iran: a qualitative study. Health Emerg Disasters Q. 2015;1(1):33-42. 